Article

\title{
Assessing the Analytical Solution of One-Dimensional Gravity Wave Model Equations Using Dam-Break Experimental Measurements
}

\author{
Wenjun Liu, Bo Wang *, Yunliang Chen, Chao Wu and Xin Liu \\ State Key Laboratory of Hydraulics and Mountain River Engineering, Sichuan University, \\ Chengdu 610065, China; Liuwenjun_SCU@163.com (W.L.); liangyunchen@163.com (Y.C.); \\ wuchao_w@163.com (C.W.); Liuxin_SCU@163.com (X.L.) \\ * Correspondence: wangbo@scu.edu.cn; Tel.: +86-028-8540-1144
}

Received: 19 August 2018; Accepted: 13 September 2018; Published: 15 September 2018

\begin{abstract}
The one-dimensional gravity wave model (GWM) is the result of ignoring the convection term in the Saint-Venant Equations (SVEs), and has the characteristics of fast numerical calculation and low stability requirements. To study its performances and limitations in 1D dam-break flood, this paper verifies the model using a dam-break experiment. The experiment was carried out in a large-scale flume with depth ratios (initial downstream water depth divided by upstream water depth) divided into 0 and $0.1 \sim 0.4$. The data were collected by image processing technology, and the hydraulic parameters, such as water depth, flow discharge, and wave velocity, were selected for comparison. The experimental results show that the 1D GWM performs an area with constant hydraulic parameters, which is quite different from the experimental results in the dry downstream case. For a depth ratio of 0.1 , the second weak discontinuity point, which is connected to the steady zone in the 1D GWM, moves upstream, which is contrary to the experimental situation. For depth ratios of $0.2 \sim 0.4$, the moving velocity of the second weak discontinuity point is faster than the experimental value, while the velocity of the shock wave is slower. However, as the water depth ratio increases, the hydraulic parameters calculated by 1D GWM in the steady zone gradually approach the experimental value.
\end{abstract}

Keywords: gravity wave model; dam-break flood; image processing technology; experimental study

\section{Introduction}

The dam-breaking flood problem has been of wide concern in academic and engineering circles due to its importance and complexity; once the dam fails, it will cause huge numbers of casualties and property losses [1-3]. Ritter derived a theoretical solution of the dam-breaking flood problem in a rectangular prismatic channel that has a flat bottom and no resistance with a dry bed downstream [4]. Based on Ritter's solution, Stoker derived the theoretical solution of instantaneous dam failure in the rectangular prismatic channel for stationary water downstream [5]. Considering that actual rivers often have a certain slope, many scholars have tried to add this factor into the analytical model. Hunt derived an approximate solution for the dam failure of a rectangular prismatic channel in the case of a declining bottom [6]. In addition, actual river channels are mostly irregular, and their cross-sections cannot be simplified into rectangles. Wang et al. derived an analytical solution for the collapse of a prismatic channel with an arbitrary cross-sectional shape under a tilted channel [7]. Due to the occurrence of undular bore waves in nature, some physical models have been proposed based on a nonhydrostatic pressure assumption in dam break flows [8-10]. Since the current analytical model is still quite simplified compared to actual situations, it is necessary to conduct much experimental 
research. Stansby et al. systematically studied the initial shape of 1D dam failure. The analysis shows that at the initial stage of dam break, a mushroom-like jet occurs downstream [11]. Aleixo et al. used particle tracking velocimetry (PTV) to measure the cross-sectional velocity of the 1D dam-breaking flow and obtained a more accurate distribution of the cross-sectional flow velocity [12]. LaRocque et al. used an ultrasonic velocity profiler (UVP) to study the vertical velocity distribution in a rectangular flume and compared the different turbulence models to simulate the dam flow, and the large eddy simulation (LES) performed better than other models [13]. Many dam break experiments have also been carried out in the case of a moving bed to further approach the actual situation [14-16]. Recently, image processing technology has been used to experimentally study dam-break flood movements [17-21]. Because the equipment is not immersed, the measurement does not interfere with the flow field, and the whole measuring process is easy to program; furthermore, the cost is relatively low compared with that of high-precision equipment such as particle image velocimetry (PIV) or PTV, and its application prospects are quite extensive [22].

Certain problems, such as a long calculation time and unstable or divergent calculations, often exist in solving shallow water equations (SWEs). To solve these problems, on the one hand, many scholars use some excellent numerical schemes or commercial software to simulate them [23-25], and the lattice boltzmann model (LBM) performs very well for dealing with SWEs under many different boundary conditions [26-34]; smoothed particle hydrodynamics (SPH) can also give sufficient simulation accuracy in urban flood and 2D dam break flood problems [35-37], but on the other hand, when some items in the equation are negligible compared to others in some actual physical phenomena, many researchers have also tried to simplify the equations [38-43]. Among the simplified models, zero-inertia (or diffusive wave) models seem to need more computing time for flood simulation, and their reliability is significantly affected by complex topographic information; they give poor predictions of events around buildings, especially in urban districts [38,40,41,43]. Local inertial approximation (or gravity wave model) has good agreement with full-dynamic models when $\mathrm{Fr}<0.5$, leads to milder water depth gradients in steady flow, and has slower flood propagation speeds in unsteady flow. However, it requires less computing time, and is a faster alternative for gradually varied subcritical flows where domain-average friction typically exceeds $n=0.03[39,40,42]$. Most previous methods for studying these simplified models include numerical analysis; Martins et al. derived a simplified analytical solution for the 1D gravity wave model (GWM) and compared it with the analytical solution of the Saint-Venant Equation (SVE) in dam break flow [44]. After using the MacCormack and Roe scheme to simulate the simplified equations [45], the author found that the 1D GWM was similar to the analytical solution of the SVE when there was a subcritical flow downstream and the shock wave velocity was relatively small, whereas the difference was large when there was no water downstream. The numerical simulation does not need special initial conditions to remain steady and has good agreement with the derived simplified analytical solution.

However, the work of Martins did not analyze the relationship between the 1D GWM and the actual dam-breaking flow in detail, and the only two cases (dry and wet bed downstream) selected for comparison with SVE seemed to be insufficient. The ability of the 1D GWM to capture the 1D dam break flow characteristics and whether it can be used as a simplified alternative model outside the SVE need to be verified by experiment. This study carried out a large number of dam-break experiments in a large-scale water flume and used a non-immersion image processing technology to collect experimental data. Depth ratios (initial downstream water depth divided by upstream water depth) of 0 and $0.1 \sim 0.4$ were considered for an upstream head of $0.6 \mathrm{~m}$. Hydraulic parameters, such as water depth, flow discharge, average flow velocity, Froude number, and wave velocity, were measured or calculated. Through detailed comparison of the experimental data and the analytical solution of the 1D GWM, the ability of the 1D GWM to describe the characteristics of 1D dam-break flood movement was analyzed, and a valuable reference for using this model to calculate 1D dam-break flows in the future was created. 


\section{Materials and Methods}

\subsection{Flume and Other Instruments}

The flume was made of tempered glass supported by a steel frame. The upstream was $8.37 \mathrm{~m}$ long, and the downstream $9.63 \mathrm{~m}$ long. The width was $1 \mathrm{~m}$, and the height was $1.09 \mathrm{~m}$. The flume had a rectangular cross section and a flat bottom. The gate material was a 15-mm-thick fiberglass board, which was lifted instantly by the electromagnetic brake asynchronous motor. This method was used to simulate the instantaneous break of the dam. The lifting time was $0.27 \mathrm{~s}$ when the upstream water depth was $0.6 \mathrm{~m}$, which satisfies the following transient failure condition [46]: $t<\left(2 h_{u} / g\right)^{1 / 2}=0.3499 \mathrm{~s}$ ( $h_{u}$ is the upstream water depth, and $g$ is the gravity acceleration, $9.8 \mathrm{~m} / \mathrm{s}^{2}$ ). Eight CCD (charge coupled device) cameras were arranged in parallel at the side of the flume at a distance of $1.4 \mathrm{~m}$ to capture the evolution of the water flow. To ensure the quality of the video and make it more convenient to use the image processing technology, the background was covered with a smooth white car sticker, and the water was dyed in the experiment. To avoid noise from the reflection of the flume glass during image processing, a light-colored curtain was arranged on both sides of the flume to eliminate the shadow caused by natural light. In the experiment, 8 CCD cameras were simultaneously turned on by a wireless remote control. A wide-angle lens with a resolution of $1440 \times 1920$ was used for shooting, and the shooting speed was 48 frames per second. The device schematic is shown in Figure 1.

\section{(a) Side view}

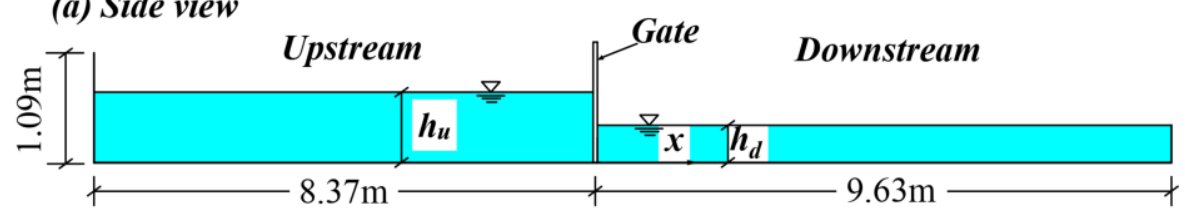

(b) Top view

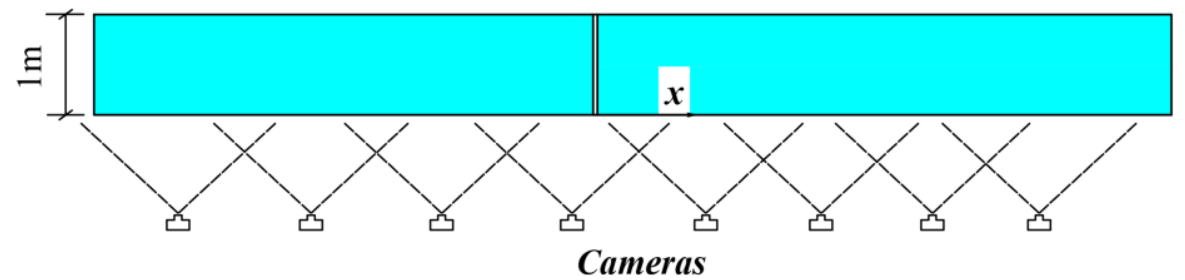

Figure 1. Schematic of the experimental device: (a) side view; (b) top view

\subsection{Data Acquisition Technology and Experimental Repeatability Verification}

The process of experimental data acquisition is divided into two main steps: the first step is to obtain the external and internal parameters of each camera by using the calibration plate and the calibration toolbox in MATLAB (MATLAB2016a, Mathworks company, Natick, MA, USA) and then to use the data and the corresponding calibration function to re-project and obtain the undistorted image. The second step is to analyze the image based on the undistorted image. In addition, the calibrated picture is then cropped and merged using the ruler above the flume. After binarizing the image, the water depth at each location can be obtained by boundary recognition functions. The calibration plate is shown in Figure 2a. The size of the square lattice in the plate is $100 \mathrm{~mm} \times 100 \mathrm{~mm}$. The number of grids is 11 on one side and 10 on the other. A margin of $50 \mathrm{~mm}$ is left around the calibration plate for the calibration toolbox to recognize the corner points so that the internal and external parameters of each camera can be accurately obtained to better correct the distortion. A set of 25 pictures in different orientations and angles is used to calibrate each camera, and the pictures before and after calibration are shown in Figure $2 b, c$. The actual length represented by one pixel is approximately $1.8 \mathrm{~mm}$, and the depth of the part blocked by the flume steel column is obtained by interpolation. The picture after clipping and binarization is shown in Figure 3. 


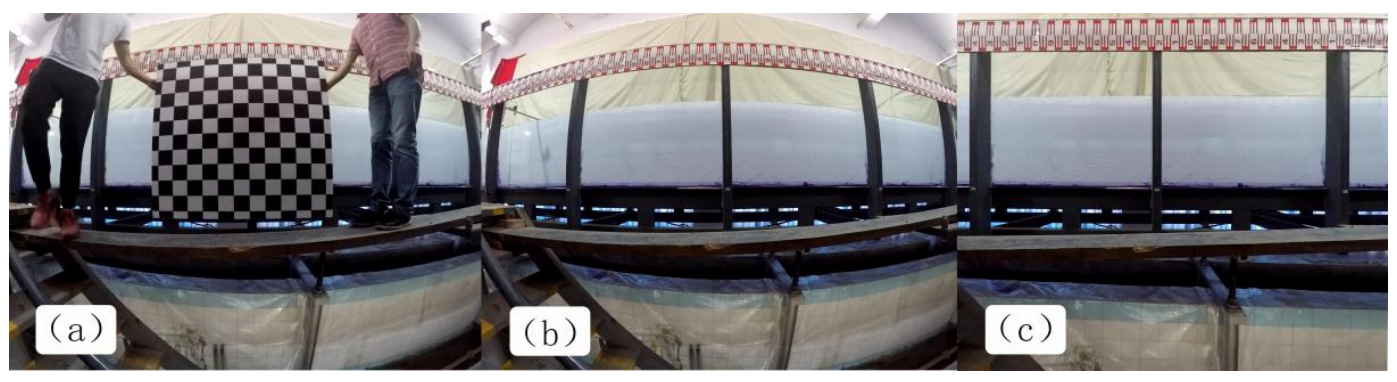

Figure 2. Picture calibration: (a) calibration board; (b) original image; (c) calibrated image.

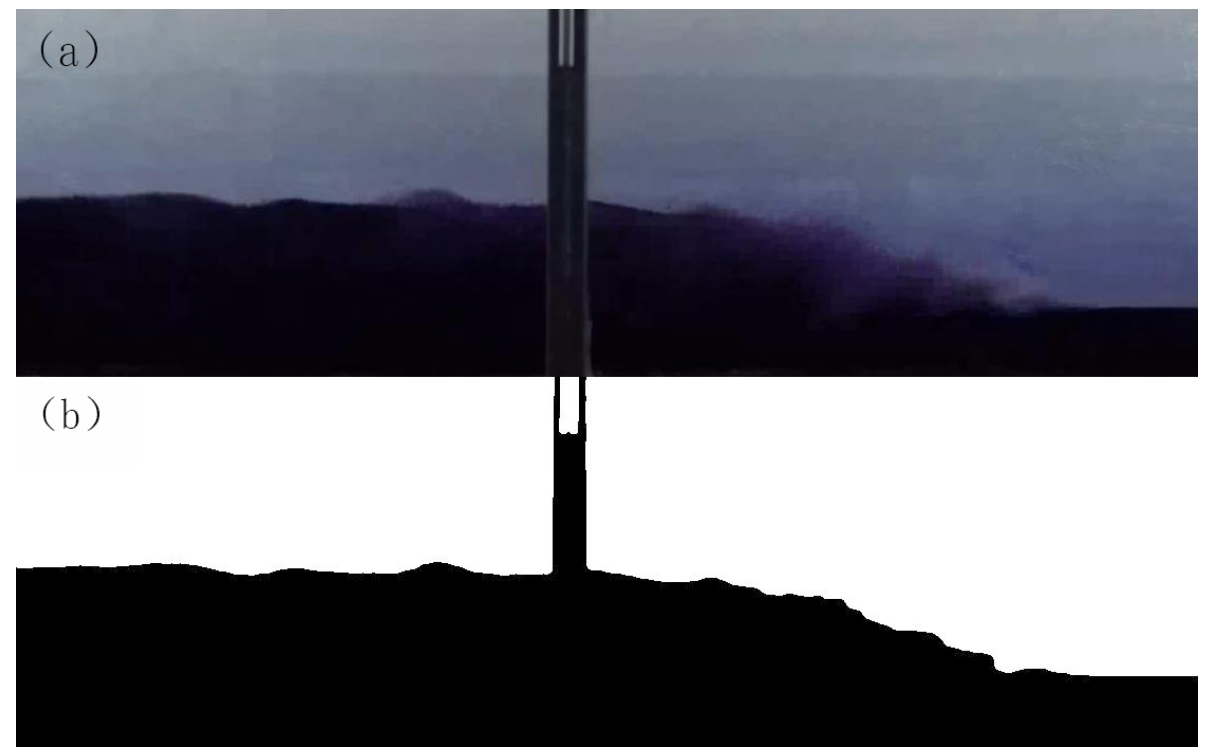

Figure 3. Picture binarization. (a) original image; (b) binarized image.

The depth ratio is defined as $\alpha=h_{d} / h_{u}$, where $h_{u}$ and $h_{d}$ are the upstream and downstream initial water depths, respectively. The experimental conditions are shown in Table 1:

Table 1. Experimental conditions.

\begin{tabular}{cccccc}
\hline \multirow{2}{*}{$h_{u}(\mathrm{~m})$} & \multicolumn{5}{c}{$\boldsymbol{h}_{d}(\mathrm{~m})$} \\
\cline { 2 - 6 } & $\alpha=\mathbf{0}$ & $\alpha=\mathbf{0 . 1}$ & $\alpha=\mathbf{0 . 2}$ & $\boldsymbol{\alpha}=\mathbf{0 . 3}$ & $\alpha=\mathbf{0 . 4}$ \\
\hline 0.6 & 0 & 0.06 & 0.12 & 0.18 & 0.24 \\
\hline
\end{tabular}

To ensure the stability and accuracy of the experimental data collection, the repeatability of the experiment is verified here by repeating the conditions of $h_{u}=0.6 \mathrm{~m}$ and $h_{d}=0 \mathrm{~m}$ and comparing the depth data at positions of $x=0.3 \mathrm{~m}$ (near the dam) and $x=4.5 \mathrm{~m}$ (far from the dam). The results are shown in Figure 4, where Run 1 and Run 2 represent the first and second experiments for the conditions of $h_{u}=0.6 \mathrm{~m}$ and $h_{d}=0 \mathrm{~m}$, respectively. It can be seen that the overlap of the data between the two groups is quite good, and $R^{2}$ is close to 1 , which proves that the experiment has good repeatability. 

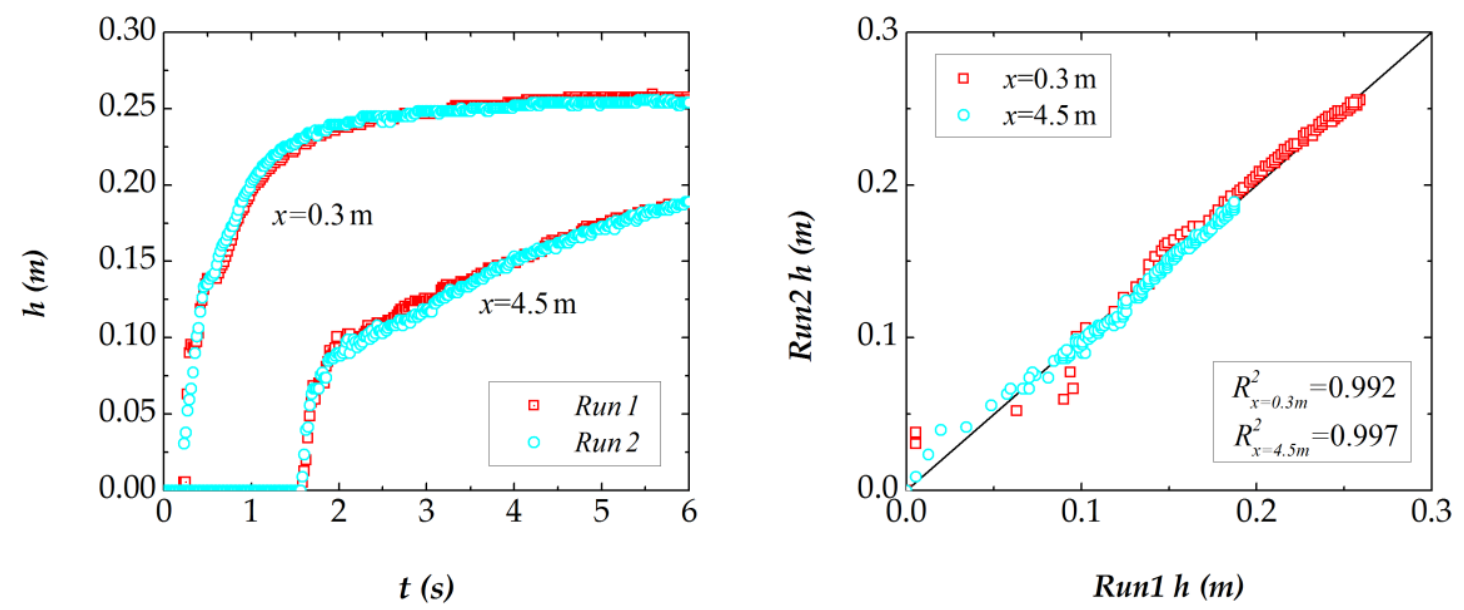

Figure 4. Experimental repeatability verification.

\section{Results}

\subsection{Dry Bed Downstream Condition}

\subsubsection{Water Depth, Flow Discharge, Average Velocity and Fr}

Here, the hydraulic parameters involved are dimensionless in the following formulas:

$$
\begin{gathered}
X=\frac{x}{t \sqrt{g h_{u}}} \\
T=\frac{t}{\sqrt{h_{u} / g}} \\
H=\frac{h}{h_{u}} \\
U=\frac{u}{\sqrt{g h_{u}}}
\end{gathered}
$$

where $h, u$ are water depth and flow velocity; $X, T, H$, and $U$ are the dimensionless position, time, water depth, and flow velocity, respectively,

The method for calculating flow discharge in the experiment is similar to those of Bento et al. [47] and Cestero et al. [48]; that is, calculate the water body area of the façade by the water depth data at each position for a certain time, because it is a one-dimensional case, then multiply the width of the flume to obtain the volume of the cross section at a certain moment. The following formula is used to calculate the flow discharge:

$$
Q_{(t)}=\frac{V_{(t+\Delta t)}-V_{(t)}}{\Delta t}
$$

where $Q_{(t)}$ is the flow discharge for time $t, V_{(t)}$ is the water volume between a cross section and the end of the upstream reservoir at time $t, V_{(t+\Delta t)}$ is the water volume between a cross section and the end of the upstream reservoir at time $t+\Delta t$, and $\Delta t$ is the time difference of $1 / 48 \mathrm{~s}$.

For convenience of later description, the analytical solution of 1D GWM is simply explanation here. Martins divided the structure of dam break into four areas, as shown in Figure 5, where $P_{1 u}$ and $P_{12}$ represent the first and second weak discontinuity point, respectively; $P_{2 d}$ represents the strong discontinuity point; $\xi$ represents the downstream wave-front evolution velocity; $h_{1}$ and $h_{2}$ represent the water depth in the rarefaction wave zone and the steady zone, respectively; $C_{u}$ and $C_{2}$ represent the velocity of the first and second weak discontinuity point, respectively. 


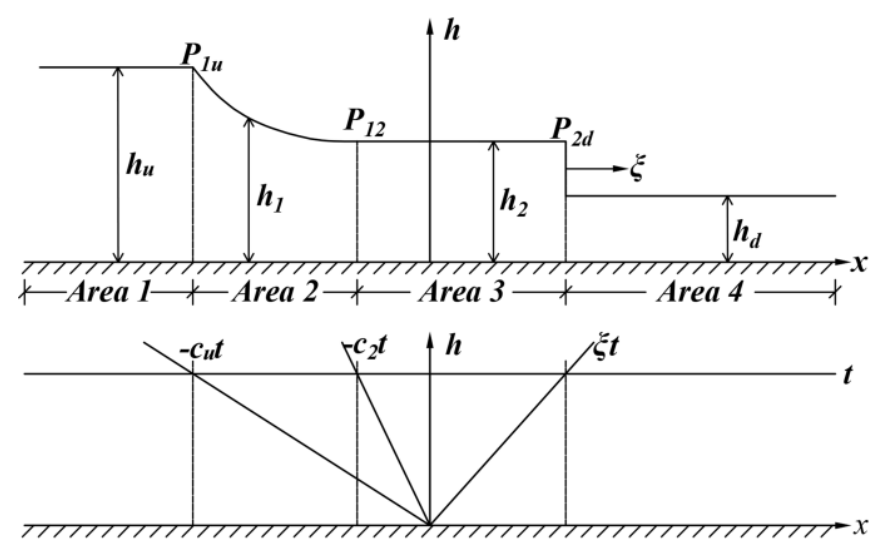

Figure 5. Dam break flood evolution model.

Using the method of characteristics (MOC) and performing some formula operations, the analytical formulas for the 1D GWM in four areas are shown in Table 2, where $C_{1}$ and $C_{d}$ are celerity-velocity in Area2 and Area4, respectively; $U_{1}$ and $U_{2}$ are average flow velocity in Area2 and Area3, respectively.

Table 2. Analytical formulas for 1D GWM in four areas.

\begin{tabular}{ccccc}
\hline Variable & Area 1 & Area 2 & Area 3 & Area 4 \\
\hline$h$ & $h_{u}$ & $h_{1}=x^{2} / g t^{2}$ & $h_{2}=c_{2}^{2} / g$ & $h_{d}$ \\
$c$ & $c_{u}=\sqrt{g h_{u}}$ & $c_{1}=-x / t$ & $c_{2}^{3}=c_{u}^{3}+3 / 2\left(c_{d}^{2}-c_{2}^{2}\right) \sqrt{\left(c_{d}^{2}+c_{2}^{2}\right) / 2}$ & $c_{d}=\sqrt{g h_{d}}$ \\
$u$ & 0 & $u_{1}=2\left(c_{1}^{3} t^{3}+x^{3}\right) / 3 x^{2} t$ & $u_{2}=2 / 3\left(c_{u}^{3} / c_{2}^{2}-c_{2}\right)$ & 0 \\
$\xi$ & - & - & $\xi=\sqrt{\left(c_{d}^{2}+c_{2}^{2}\right) / 2}$ & - \\
$P$ & $-c_{u} t$ & $-c_{2} t$ & $\xi t$ & - \\
\hline
\end{tabular}

Under the dry bed downstream condition, the hydraulic parameters calculated by the 1D GWM are very different from those of the experiment, as shown in Figure 6, where Exp. and Fr represent the experimental results and Froude number. According to the analytical solution of Martins, the water depth of area 3 still exists when there is no water in the downstream, which is quite different from the actual situation. The 1D GWM cannot accurately describe the evolution of 1D dam-break flow when there is no water downstream. 

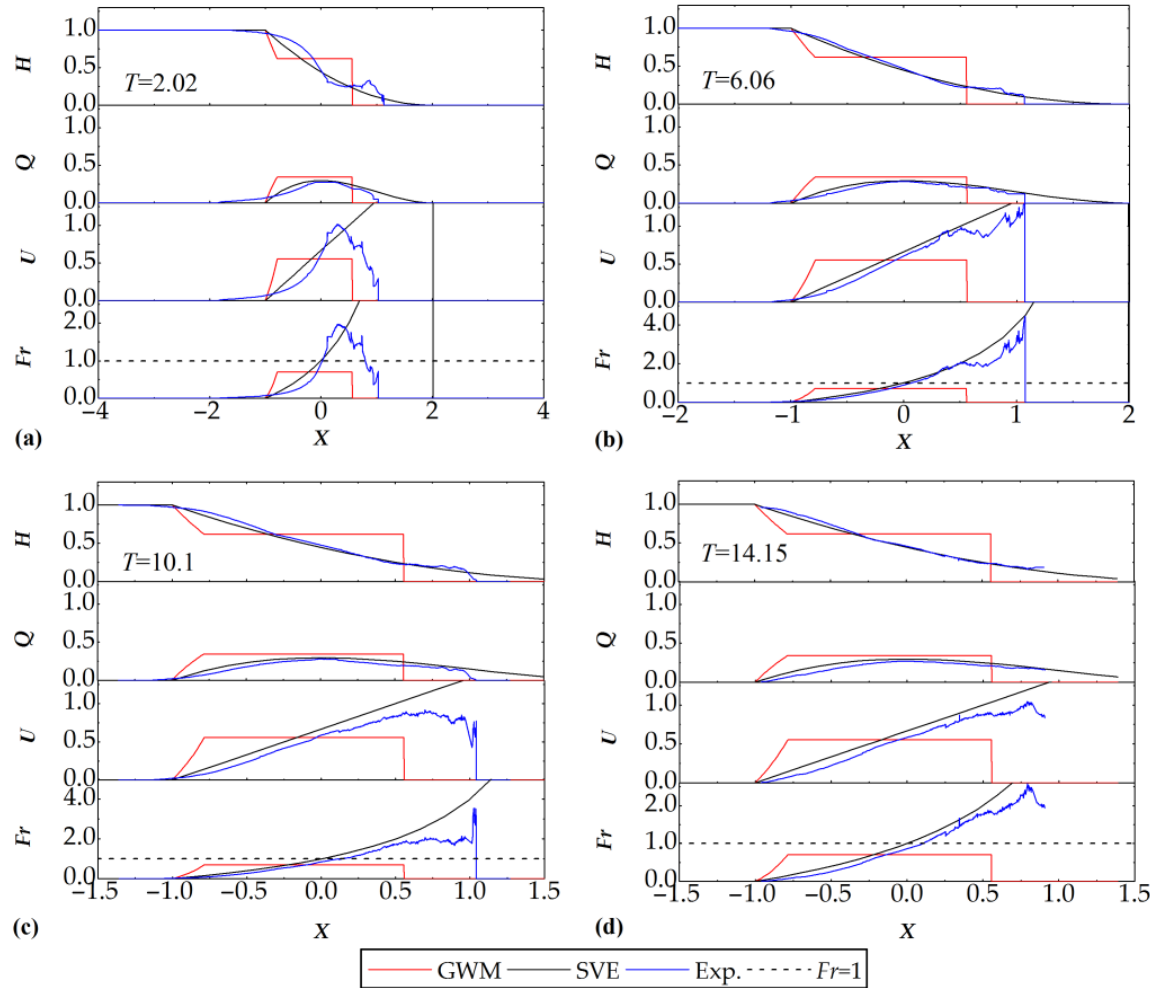

Figure 6. Water depth, flow discharge, average velocity and $F r$ for dry bed downstream: (a) $T=2.02$; (b) $T=6.06$; (c) $T=10.1 ;$ (d) $T=14.15$.

\subsubsection{Upstream Negative Wave and Downstream Wave-Front Velocities for Dry Bed Downstream}

The calculation results of the upstream negative wave and the downstream wave-front velocities are shown in Figure 7 , where $U_{n}$ represents the dimensionless upstream negative wave evolution velocity and $\xi_{n}$ represents the dimensionless downstream wave-front evolution velocity. Here, the relative root mean square error (RRMSE) is used to compare the error between the calculated value and the experimental value. The formula is as follows:

$$
R R M S E=\sqrt{\frac{1}{n} \sum_{i=1}^{n}\left(\frac{y_{i}-\mu_{i}}{\mu_{i}}\right)^{2}} \times 100 \%
$$

where RRMSE represents the relative root mean square error, $n$ is the total number of all measured data points, $y_{i}$ is the model calculated value, and $\mu_{i}$ is the measured value.
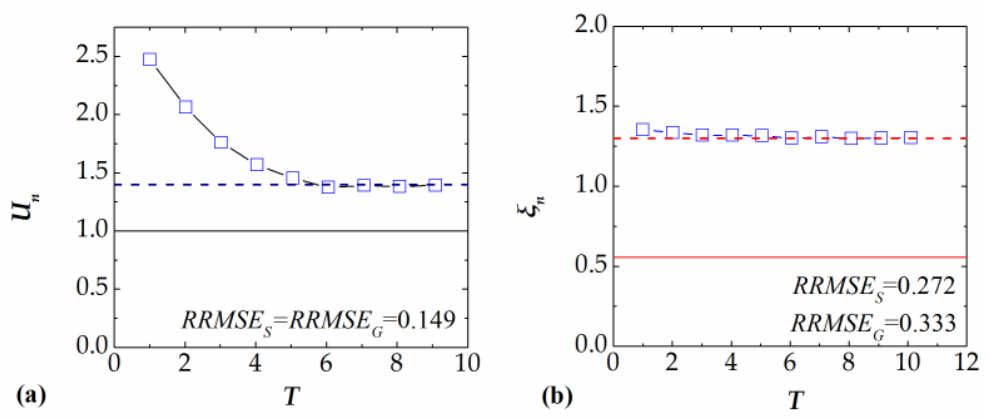

GWM - SVE - $\square-$ Exp. $-\cdots \xi_{n}=1.3-\cdots \cdot U_{n}=1.4$

Figure 7. Velocities of (a) the upstream negative wave and (b) the downstream wave-front. 


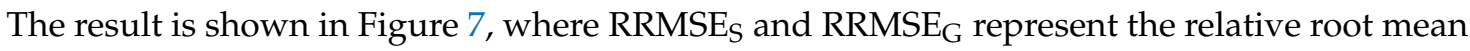
square error for SVE and 1D GWM, respectively. In the dry bed downstream case, the upstream negative wave velocities calculated by the ID GWM and SVE are the same. The negative wave velocity gradually decreases and then stabilizes at approximately 1.4 in the experiment, Lauber and Hager explained that it is caused by excessive curvature of the streamline [46]. While the evolution velocity of the downstream wave-front basically remains stable, the dimensionless velocity is approximately 1.3 due to the resistance, which is smaller than the value of 2.0 from the SVE and much larger than the value of 0.55 calculated by the 1D GWM. The upstream negative wave and downstream wave-front speeds obtained by Leal et al. are all average values [49], and the characteristics of their propagation speed are not obtained over time. However, from the results of the stable speed, we can see that they are basically consistent with the results of Leal et al. [49].

\subsection{Wet Bed Downstream Condition}

\subsubsection{Water Depth}

Different degrees of water jump will occur downstream for the initial dam break $(T=2.02)$. It can be seen from Figure 8a that neither the SVE nor the 1D GWM describes this phenomenon well. Stansby et al. also observed that a mushroom-like jet occurs downstream of the initial dam break in the case of a wet bed downstream, and found that the movement form is quite complicated, but after the wave is broken, the motion of the water flow has good agreement with the analytical solution of the shallow water equations [11]. It can be seen from Figure 8 that the conclusion is still valid when the water depth ratio is between 0.1 and 0.4 .
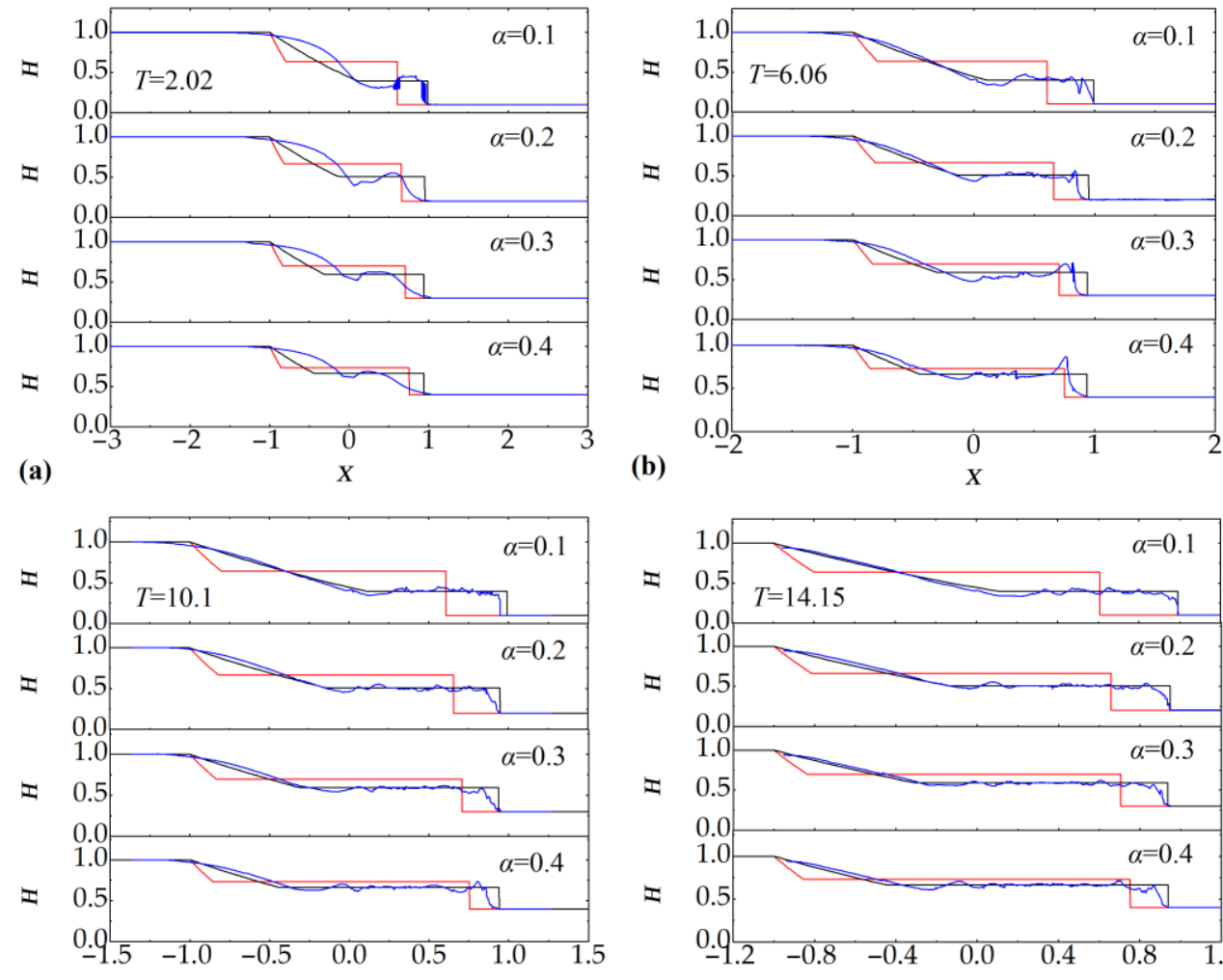

(c)

$X$
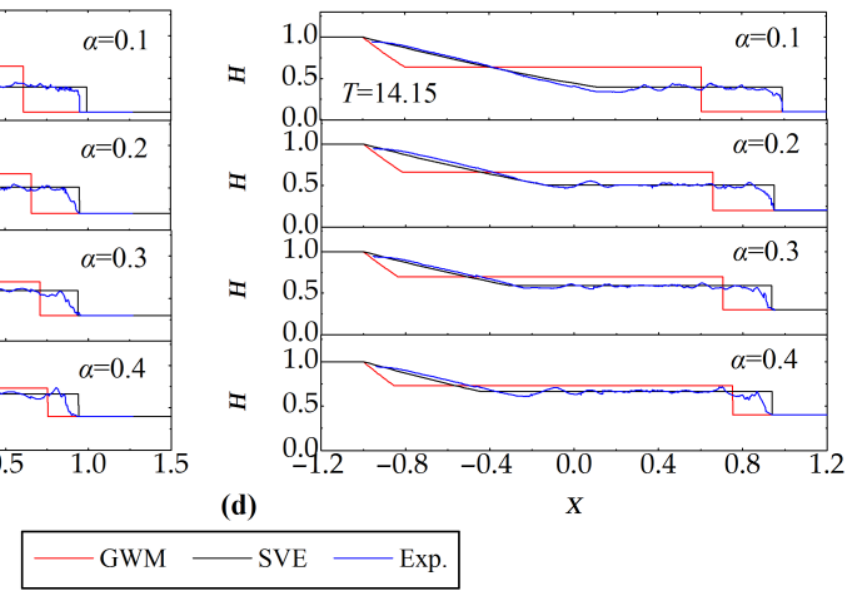

Figure 8. Water depth for wet bed downstream: (a) $T=2.02 ;(\mathbf{b}) T=6.06 ;(\mathbf{c}) T=10.1 ;(\mathbf{d}) T=14.15$. 
When $\alpha=0.1$, the 1D GWM shows that the second weak discontinuity point moves upstream, but the experimental results are just the opposite. The evolution of water flow is much closer to that of the SVE. As Martins [44] stated, the 1D GWM shows only one subcritical flow state. When $\alpha=0.2 \sim 0.4$, the second weak discontinuity point moves upstream in the experiment, but the range of the rarefaction wave zone calculated by the 1D GWM is shorter than that of the experiment. The speed at which the second weak discontinuity point moves upstream is much faster than the experimental value; the speed is $498 \%, 180 \%$, and $94.7 \%$ faster than the experimental value for $\alpha=0.2,0.3$, and 0.4 , respectively. In addition, the water depth of the steady zone calculated by the 1D GWM is higher than the experimental value, but it can be seen that as the water depth ratio increases, the water depth gradually approaches the experimental value.

\subsubsection{Flow Discharge}

In the case of wet bed downstream, the downstream water surface is distorted in the initial stage of dam break. The leaping water body will spin and aerate, and there will also be holes in the water body when it evolves downstream. Thus, the shape of the water surface line is complicated and not easy to capture. The flow discharge obtained by the above method cannot accurately describe the actual change, so the calculation of flow discharge in the case of wet bed downstream starts from $T=6.06$. The calculation result is shown in Figure 9. It can be seen that due to the shortening of the rarefaction wave zone calculated by the 1D GWM, there is a significant deviation from the experimental value throughout the evolution period. The flow discharge in the steady zone is larger than the experimental value, but it can be seen that with the water depth ratio increased, the flow discharge value calculated by the 1D GWM in the steady zone also gradually approaches the experimental value.
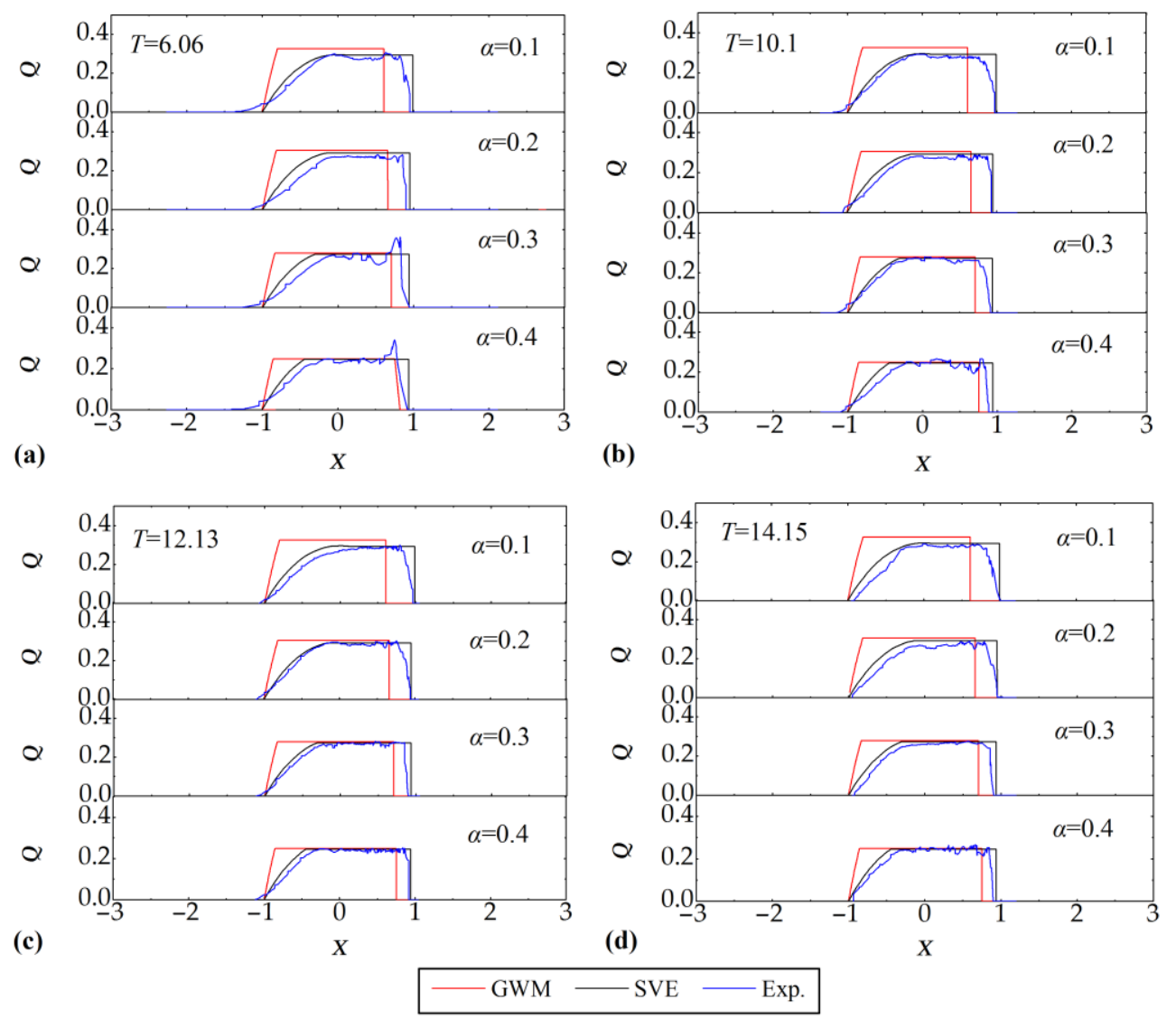

Figure 9. Flow discharge for wet bed downstream: $(\mathbf{a}) T=6.06 ;(\mathbf{b}) T=10.1 ;(\mathbf{c}) T=12.13 ;$ (d) $T=14.15$. 


\subsubsection{Average Velocity and $\mathrm{Fr}$}

The calculation results of the average velocity are shown in Figure 10. Similar to the flow discharge comparison, the average velocity calculated by the 1D GWM in the rarefaction wave zone is very different from the experimental value. The average velocity is smaller than the experimental value in the steady zone, especially when the water depth ratio is small, but it can be seen that as the water depth ratio increases, the average velocity gradually approaches the experimental value in the steady zone.
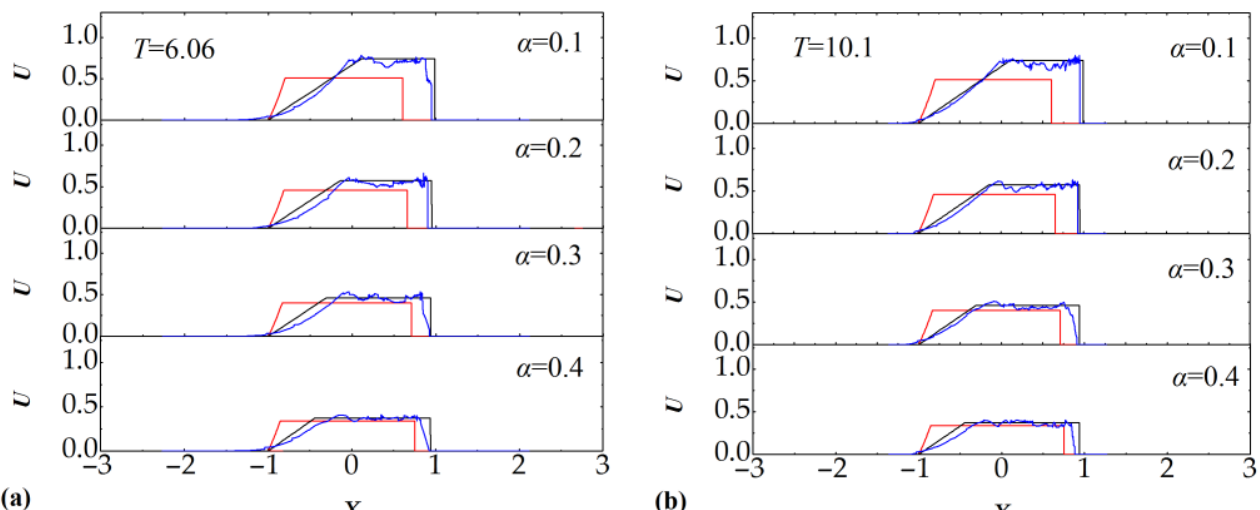

(a)

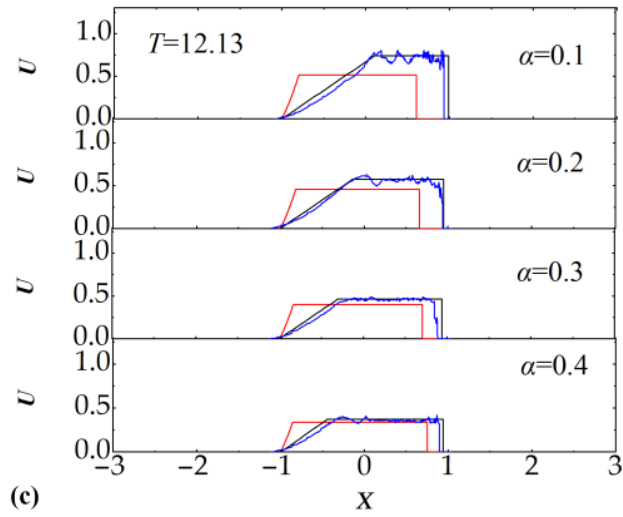

(b)

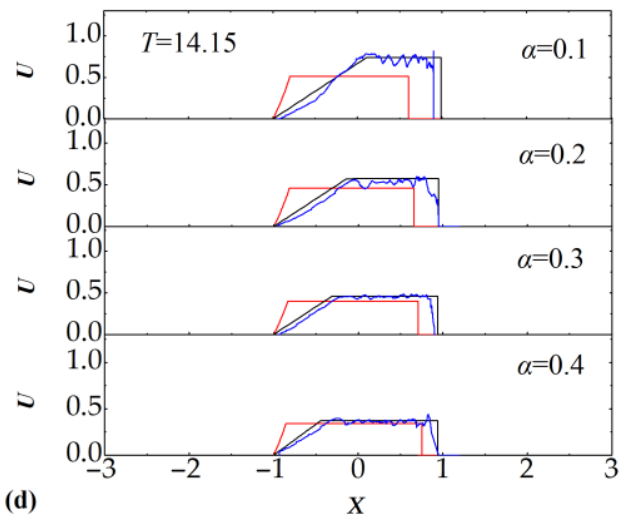

(d)

$$
\text { GWM } \longrightarrow \text { SVE } \longrightarrow \text { Exp. }
$$

Figure 10. Average velocity for wet bed downstream: $(\mathbf{a}) T=6.06 ;(\mathbf{b}) T=10.1 ;(\mathbf{c}) T=12.13 ;(\mathbf{d}) T=14.15$.

The calculation results for $F r$ are shown in Figure 11. As described above, when $\alpha=0.1$, the Fr value calculated by the 1D GWM is less than 1 in the entire flow region, and the Fr of the actual flow is greater than 1 in the steady zone. At this time, the second weak discontinuity point will not propagate upstream, and the description of the 1D GWM is flawed. When $\alpha=0.2 \sim 0.4, F r$ is less than 1 in the whole flow region, and the flow is in a subcritical flow state. The result of the 1D GWM calculation still differs greatly in the rarefaction wave zone, and the Fr calculated in the steady zone is smaller than the experimental value. However, it also has the characteristic that its value gradually approaches the experimental value as the water depth ratio increases. 

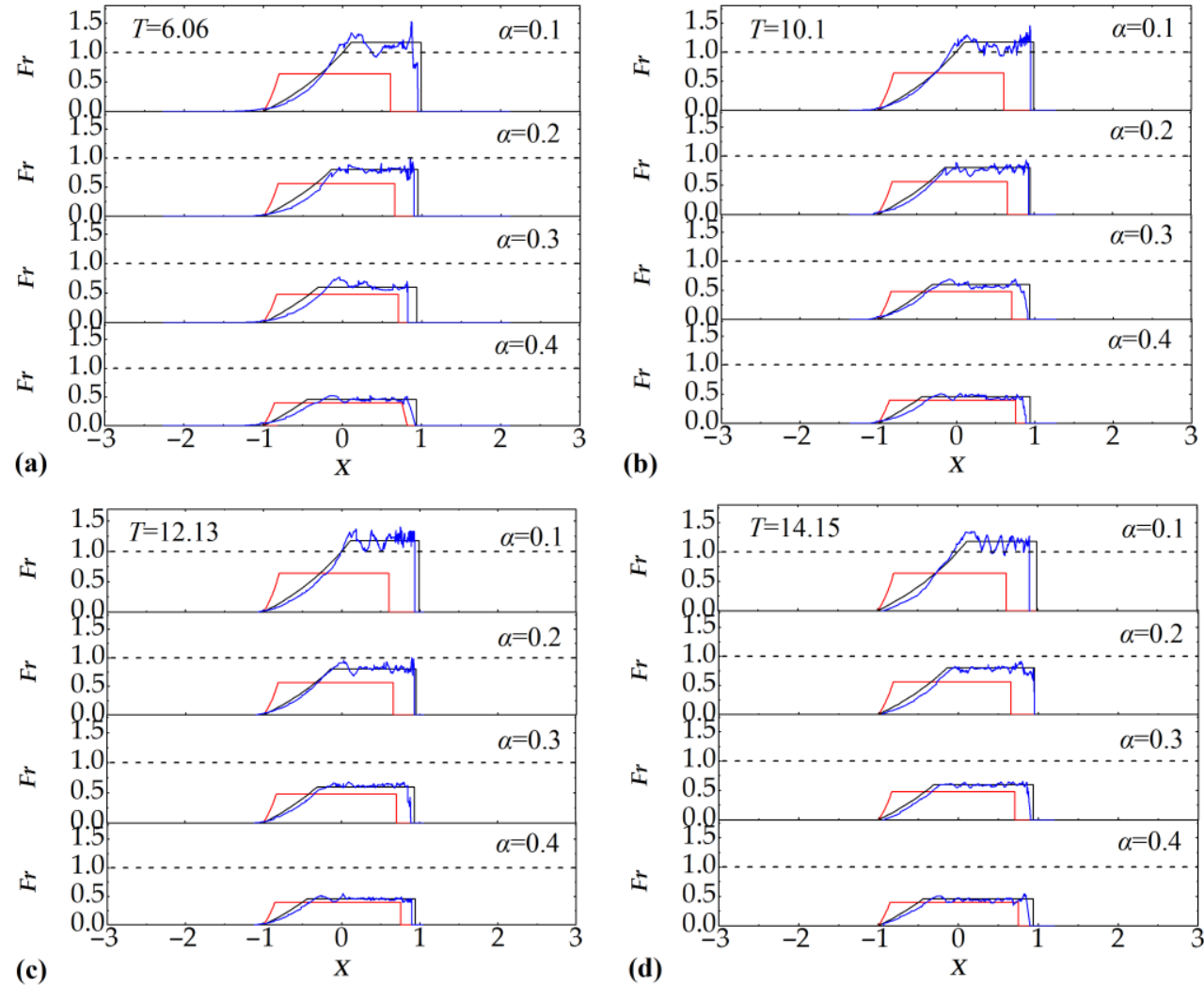
(d)

$$
\text { GWM }- \text { SVE } \longrightarrow \text { Exp. } \cdots \cdots F_{r}=1
$$

Figure 11. $F r$ for wet bed downstream: (a) $T=6.06$; (b) $T=10.1 ;$ (c) $T=12.13$; (d) $T=14.15$.

\subsubsection{Relative Error of Hydraulic Parameters in Steady Zone}

In the previous sections, it was found that although the 1D GWM has large defects in the rarefaction wave zone, the results are much closer to the experimental value in the steady zone when the water depth ratio is relatively large. Here, the error is calculated by the following formula:

$$
\delta=|y-\mu| / \mu
$$

where $y$ is the value calculated by the 1D GWM or SVE and $\mu$ is the experimental measurement value.

The calculation result is shown in Figure 12, where $\delta_{H}, \delta_{U}, \delta_{F r}$, and $\delta_{Q}$ represent the errors in the water depth, average velocity, $F r$ and flow discharge in the steady zone, respectively. It can be seen from Figure 12 that with increasing water depth ratio, the error between these hydraulic parameters and the experimental values tend to gradually decrease. When $\alpha=0.4$, the errors for water depth, average velocity, $\mathrm{Fr}$ and flow discharge are $7.91 \%, 6.32 \%, 8.36 \%$, and $3.94 \%$, respectively. 

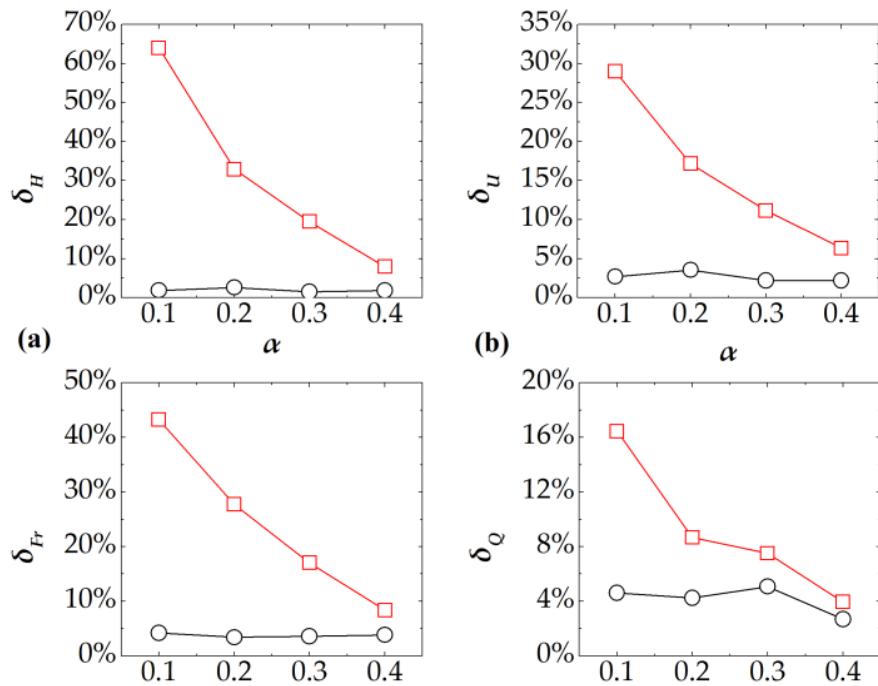

(b)

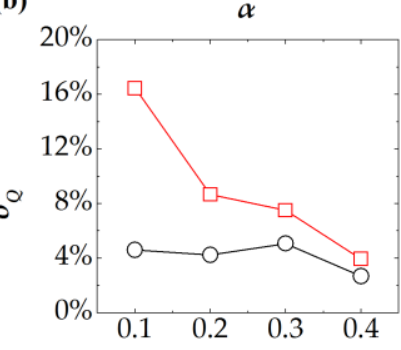

(c)

(d)

$\alpha$

$-\square-\mathrm{GWM} \longrightarrow \mathrm{O}-\mathrm{SVE}$

Figure 12. Error in the steady zone for different water depth ratios: (a) water depth; (b) average velocity; (c) Fr; (d) flow discharge.

\subsubsection{Upstream Negative Wave and Downstream Wave-Front Velocities for Wet Bed Downstream}

The calculation results of the velocity for upstream negative wave and downstream wave-front velocities for $\alpha=0.1 \sim 0.4$ are shown in Figure 13. It can be seen that the negative wave velocities calculated by the SVE and 1D GWM are the same for the wet bed downstream case, but the negative wave velocity is larger than those of the SVE or 1D GWM at the initial time point in the experiment. After the flow has evolved for a period of time, the velocity gradually decreases, and the error gradually decreases as the water depth ratio increases. The steady velocity is relatively stable in the experiment, and it is consistent with the SVE, the shock wave velocity is small for the 1D GWM. However, it should be noted that the error of shock wave velocity between the 1D GWM and the experimental value tends to gradually decrease as the water depth ratio increases.
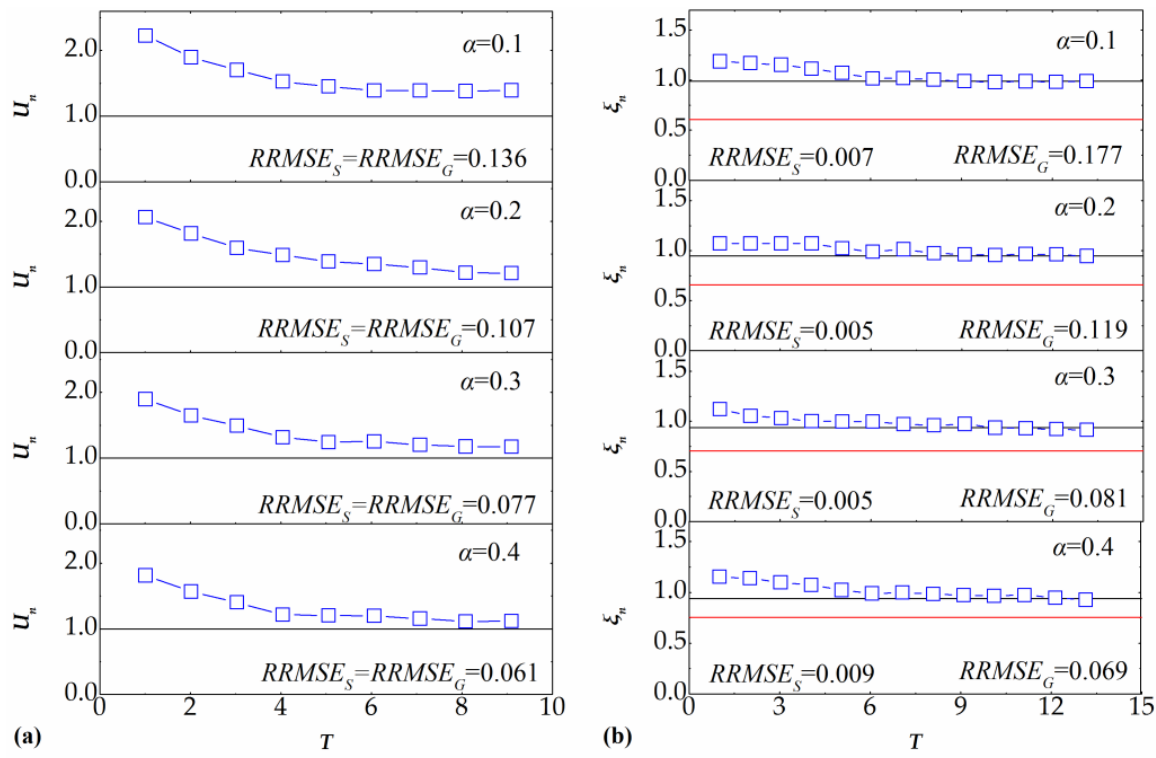

(b)

$$
\text { GWM } \longrightarrow \text { SVE } \rightarrow-\text { Exp. }
$$

Figure 13. Upstream negative wave and downstream shock wave velocities for wet bed downstream. 


\section{Discussion}

For the study of GWM, past researchers have mostly used different numerical calculation methods to solve the simplified governing equations directly $[39,40,42]$. Their work proves that the GWM requires less computing time and does not need to pay much effort to maintaining computational stability. It has certain prediction accuracy when the surface friction is not small $(n>0.03)$ in subcritical flows. In view of the above advantages of GWM, Martins tried to apply it to the 1D dam break flow and derived the analytical solution of 1D GWM under simplified conditions. However, the performances and limitations of analytical solution need to be further confirmed by experimental research [50,51]. This paper analyzes the analytical solution of 1D GWM by means of experimental research. Unlike the numerical model, which can arbitrarily control the boundary conditions and initial state to analyze the characteristics of the governing equations, both analytical and experimental research is performed under ideal boundary conditions here. 1D dam-breaking flow is a kind of unsteady flow in open channel, which has special evolution characteristics and need targeted analysis. In the experiment, we have observed that 1D GMW has a great difference with experimental conditions in the case of dry bed downstream, the calculated rarefaction wave zone is significantly shorter than the experimental one when the depth ratio is $0.1 \sim 0.4$, and the wave-front evolution speed is slower. When the depth ratio is 0.4 , the value calculated in the steady zone is close to the experimental value. It can be seen that the application of the 1D GWM to 1D dam break flow should be careful and significantly consider the influence of depth ratio.

Of course, unlike the previous numerical model studies, the experiment cannot capture the characteristics of dam break flood for very far from the dam (De Almeida and Bates $5000 \mathrm{~m}$, Bates et al. $5000 \mathrm{~m}$, Neal et al. 10,000 m). In this article, we compared the experimental result with the analytical solution of 1D GWM in a basic way. Future work could consider changing the boundary conditions for 1D GWM, such as the analytical solution of 1D GWM, considering the river bed slope or the shape of the cross-section (triangular, parabolic, etc.), and the corresponding experimental research could be carried out simultaneously. Because the frictional resistance has a great impact on GWM [39,40], considering different friction coefficients for the river bed material in the experiment is also a research direction.

\section{Conclusions}

This paper compares the data obtained by image processing technology with one-dimensional GWM in dam-break flood. Because the current test results are obtained under very simplified conditions, and for more complicated cases, further experiments or numerical simulation studies are needed in future, but at present we can draw the following conclusions:

(1) The calculated result of the 1D GWM is very different from the experimental value for dry bed downstream. There is still a region with the same hydraulic parameters value downstream that does not appear in the experiment. The 1D GWM gives a poor description for the dam-break flow movement in the dry bed downstream case.

(2) When $\alpha=0.1$, the second weak discontinuity point calculated by the 1D GWM is continuously developed upstream, which is contrary to the experimental results. When $\alpha=0.2 \sim 0.4$, the rarefaction wave zone of the 1D GWM is significantly shorter than that of the experiment, and the shock wave evolution distance is smaller than the experimental value.

(3) When $\alpha=0.1 \sim 0.4$, the relative errors in the water depth, average velocity, $F r$ and flow discharge in the steady zone gradually decrease as the water depth ratio increases. When $\alpha=0.4$, the errors are $7.91 \%, 6.32 \%, 8.36 \%$, and $3.94 \%$, respectively. The upstream negative wave speeds for the $1 \mathrm{D}$ GWM and SVE are the same, but both are smaller than the experimental value. The downstream shock speed for the 1D GWM is smaller than the experimental value. However, as the water depth ratio increases, the errors in the upstream negative wave and downstream shock wave velocities are also reduced. When $\alpha=0.4$, the RRMSE values are 0.061 and 0.069 , respectively. 
Author Contributions: Conceptualization, B.W. and C.W.; Methodology, W.L., B.W. and X.L.; Software, W.L. and X.L.; Validation, B.W. and Y.C.; Formal Analysis, B.W.; Investigation, W.L. and B.W.; Resources, Y.C.; Data Curation, W.L.; Writing-Original Draft Preparation, W.L. and B.W.; Writing-Review \& Editing, W.L. and B.W.; Visualization, W.L. and X.L.; Supervision, B.W.; Project Administration, B.W.; Funding Acquisition, B.W.

Funding: This research was funded by the National Key Research and Development Program of China (Grant No: 2016YFC0401707), the financial support of National Natural Science Foundation of China (No: 51879179) and the Sichuan Provincial Youth Science and Technology Innovation Research Team Special Funding Project (No.2016TD0020).

Conflicts of Interest: The authors declare no conflict of interest.

\section{References}

1. Haltas, I.; Tayfur, G.; Elci, S. Two-dimensional numerical modeling of flood wave propagation in an urban area due to Ürkmez dam-break, İzmir, Turkey. Nat. Hazards 2016, 81, 2103-2119. [CrossRef]

2. Kim, B.; Sanders, B.F. Dam-Break Flood Model Uncertainty Assessment: Case Study of Extreme Flooding with Multiple Dam Failures in Gangneung, South Korea. J. Hydraul. Eng. 2016, 142, 05016002. [CrossRef]

3. Bosa, S. A Numerical Model of the Wave that Overtopped the Vajont Dam in 1963. Water Resour. Manag. 2013, 27, 1763-1779. [CrossRef]

4. Ritter, A. The propagation of water waves. Ver Deutsh Ing. Z. 1892, 36, 947-954.

5. Stoker, J.J. Water Waves; Interscience Publishers, Inc.: New York, NY, USA, 1957.

6. Hunt, B. Asymptotic solution for dam-break on sloping channel. J. Hydraul. Eng. 1983, 109, $1698-1706$. [CrossRef]

7. Wang, B.; Chen, Y.; Wu, C.; Peng, Y.; Ma, X.; Song, J.J. Analytical solution of dam-break flood wave propagation in a dry sloped channel with an irregular-shaped cross-section. J. Hydro-Environ. Res. 2016, 14, 93-104. [CrossRef]

8. Frazao, S.S.; Zech, Y. Undular bores and secondary waves -Experiments and hybrid finite-volume modelling. J. Hydraul. Res. 2003, 40, 33-43. [CrossRef]

9. Kim, D.H.; Lynett, P.J. Dispersive and Nonhydrostatic Pressure Effects at the Front of Surge. J. Hydraul. Eng. 2011, 137, 754-765. [CrossRef]

10. Cantero-Chinchilla, F.N.; Castro-Orgaz, O.; Dey, S.; Ayuso, J.L. Nonhydrostatic dam break flows. I: Physical equations and numerical schemes. J. Hydraul. Eng. 2016, 142, 04016068. [CrossRef]

11. Stansby, P.K.; Tcd, B.; Chegini, A. The initial stages of dam-break flow. J. Fluid Mech. 1998, 374, $407-424$. [CrossRef]

12. Aleixo, R.; Soares-Frazão, S.; Zech, Y. Velocity-field measurements in a dam-break flow using a PTV Voronoï imaging technique. Exp. Fluids 2011, 50, 1633-1649. [CrossRef]

13. Larocque, L.A.; Imran, J.; Chaudhry, M.H. Experimental and numerical investigations of two-dimensional dam-break flows. J. Hydraul. Eng. 2013, 139, 569-579. [CrossRef]

14. Qian, H.; Cao, Z.; Liu, H.; Pender, G. New experimental dataset for partial dam-break floods over mobile beds. J. Hydraul. Res. 2017, 56, 1-12. [CrossRef]

15. Soares-Frazão, S.; Canelas, R.; Cao, Z.; Cea, L.; Chaudhry, H.M.; Die Moran, A.; El Kadi, K.; Ferreira, R.; Cadórniga, I.F.; Gonzalez-Ramirez, N.; et al. Dam-break flows over mobile beds: Experiments and benchmark tests for numerical models. J. Hydraul. Res. 2012, 50, 364-375. [CrossRef]

16. Goutiere, L.; Soares-Frazão, S.; Zech, Y. Dam-break flow on mobile bed in abruptly widening channel: Experimental data. J. Hydraul. Res. 2011, 49, 367-371. [CrossRef]

17. Kocaman, S.; Ozmen-Cagatay, H. The effect of lateral channel contraction on dam-break flows: Laboratory experiment. J. Hydrol. 2012, 432-433, 145-153. [CrossRef]

18. Kocaman, S.; Ozmen-Cagatay, H. Investigation of dam-break induced shock waves impact on a vertical wall. J. Hydrol. 2015, 525, 1-12. [CrossRef]

19. Ozmen-Cagatay, H.; Kocaman, S.; Guzel, H. Investigation of dam-break flood waves in a dry channel with a hump. J. Hydro-Environ. Res. 2014, 8, 304-315. [CrossRef]

20. Soares-Frazão, S. Experiments of dam-break wave over a triangular bottom sill. J. Hydraul. Res. 2007, 45, 19-26. [CrossRef]

21. Aureli, F.; Maranzoni, A.; Mignosa, P.; Ziveri, C. An image processing technique for measuring free surface of dam-break flows. Exp. Fluids 2011, 50, 665-675. [CrossRef] 
22. Eaket, J.; Hicks, F.E. Use of stereoscopy for dam break flow measurement. J. Hydraul. Eng. 2005, 131, 24-29. [CrossRef]

23. Wu, G.; Yang, Z.; Zhang, K.; Dong, P.; Lin, Y.T. A non-equilibrium sediment transport model for dam break flow over moveable bed based on non-uniform rectangular mesh. Water 2018, 10, 616. [CrossRef]

24. $\mathrm{Lu}, \mathrm{C}$. Simulations of shallow water equations with finite difference lax-wendroff weighted essentially non-oscillatory Schemes. J. Sci. Comput. 2011, 47, 281-302. [CrossRef]

25. Macchione, F.; Costabile, P.; Costanzo, C.; Lorenzo, G.D.; Razdar, B. Dam breach modelling: Influence on downstream water levels and a proposal of a physically based module for flood propagation software. J. Hydroinform. 2016, 18. [CrossRef]

26. Peng, Y.; Zhou, J.G.; Burrows, R. Modelling the free surface flow in rectangular shallow basins by lattice boltzmann method. J. Hydraul. Eng. 2011, 137, 1680-1685. [CrossRef]

27. Peng, Y.; Zhou, J.G.; Zhang, J.M.; Liu, H.F. Lattice boltzmann modelling of shallow water flows over discontinuous beds. Int. J. Numer. Method Fluids 2014, 75, 608-619. [CrossRef]

28. Peng, Y.; Zhang, J.M.; Meng, J.P. Second order force scheme for lattice boltzmann model of shallow water flows. J. Hydraul. Res. 2017, 55, 592-597. [CrossRef]

29. Peng, Y.; Meng, J.P.; Zhang, J.M. Multispeed lattice boltzmann model with stream-collision scheme for transcritical shallow water flows. Math. Probl. Eng. 2017, 2017. [CrossRef]

30. Meng, J.P.; Gu, X.J.; Emerson, D.R.; Peng, Y.; Zhang, J.M. Discrete boltzmann model of shallow water equations with polynomial equilibria. Int. J. Mod. Phys. 2018. [CrossRef]

31. Peng, Y.; Zhou, J.G.; Burrows, R. Modelling solute transport in shallow water with the lattice Boltzmann method. Comput. Fluids 2011, 50, 181-188. [CrossRef]

32. Peng, Y.; Zhou, J.G.; Zhang, J.M.; Burrows, R. Modeling moving boundary in shallow water by LBM. Int. J. Mod. Phys. C 2013, 24,1-17. [CrossRef]

33. Peng, Y.; Zhou, J.G.; Zhang, J.M. Mixed numerical method for bed evolution. Proc. Inst. Civil Eng. Water Manag. 2015, 168, 3-15. [CrossRef]

34. Peng, Y.; Zhang, J.M.; Zhou, J.G. Lattice Boltzmann Model Using Two-Relaxation-Time for Shallow Water Equations. J. Hydraul. Eng. 2016, 142, 06015017. [CrossRef]

35. Ata, R.; Soulaïmani, A. A stabilized SPH method for inviscid shallow water flows. Int. J. Numer. Methods Fluids 2005, 47, 139-159. [CrossRef]

36. Amicarelli, A.; Albano, R.; Mirauda, D.; Agate, G.; Sole, A.; Guandalini, R. A smoothed particle hydrodynamics model for 3d solid body transport in free surface flows. Comput. Fluids 2015, 116, 205-228. [CrossRef]

37. Albano, R.; Sole, A.; Mirauda, D.; Adamowski, J. Modelling large floating bodies in urban area flash-floods via a smoothed particle hydrodynamics model. J. Hydrol. 2016, 541, 344-358. [CrossRef]

38. Moussa, R.; Bocquillon, C. On the use of the diffusive wave for modelling extreme flood events with overbank flow in the floodplain. J. Hydrol. 2009, 374, 116-135. [CrossRef]

39. Bates, P.D.; Horritt, M.S.; Fewtrell, T.J. A simple inertial formulation of the shallow water equations for efficient two-dimensional flood inundation modelling. J. Hydrol. 2010, 387, 33-45. [CrossRef]

40. Neal, J.; Villanueva, I.; Wright, N.; Fewtrell, T.; Bates, P. How much physical complexity is needed to model flood inundation? Hydrol. Process. 2012, 26, 2264-2282. [CrossRef]

41. Costabile, P.; Costanzo, C.; Macchione, F. Performances and limitations of the diffusive approximation of the 2-d shallow water equations for flood simulation in urban and rural areas. Appl. Numer. Math. 2016. [CrossRef]

42. Almeida, G.A.M.D.; Bates, P. Applicability of the local inertial approximation of the shallow water equations to flood modeling. Water Resour. Res. 2013, 49, 4833-4844. [CrossRef]

43. Aricò, C.; Nasello, C. Comparative analyses between the zero-inertia and fully dynamic models of the shallow water equations for unsteady overland flow propagation. Water 2018, 10, 44. [CrossRef]

44. Martins, R.; Leandro, J.; Djordjević, S. Analytical solution of the classical dam-break problem for the gravity wave-model equations. J. Hydraul. Eng. 2016, 142, 06016003. [CrossRef]

45. Martins, R.; Leandro, J.; Djordjević, S. Analytical and numerical solutions of the local inertial equations. Int. J. Non-Linear Mech. 2016, 81, 222-229. [CrossRef]

46. Lauber, G.; Hager, W.H. Experiments to dambreak wave: Horizontal channel. J. Hydraul. Res. 1998, 36, 291-307. [CrossRef] 
47. Bento, A.M.; Amaral, S.; Viseu, T.; Cardoso, R.; Rui, M.L.F. Direct estimate of the breach hydrograph of an overtopped earth dam. J. Hydraul. Eng. 2017, 143. [CrossRef]

48. Cestero, J.A.F.; Imran, J.; Chaudhry, M.H. Experimental investigation of the effects of soil properties on levee breach by overtopping. J. Hydraul. Eng. 2014, 141, 04014085. [CrossRef]

49. Leal, J.G.A.B.; Ferreira, R.L.; Cardoso, A.H. Dam-break waves on movable bed. In Proceedings of the Fluvial Hydraulics: River Flow 2002, Louvain-la-Neuve, Louvain-la-Neuve, Belgium, 4-6 September 2002; Bousmar, D., Zech, Y., Eds.; Balkema: Rotterdam, The Netherlands; pp. 553-563.

50. Bukreev, V.I.; Degtyarev, V.V.; Chebotnikov, A.V. Experimental verification of methods for calculating partial dam-break waves. J. Appl. Mech. Tech. Phys. 2008, 49, 754-761. [CrossRef]

51. Bukreev, V.I.; Gusev, A.V. Gravity waves due to discontinuity decay over an open-channel bottom drop. J. Appl. Mech. Tech. Phys. 2004, 44, 506-515. [CrossRef]

C 2018 by the authors. Licensee MDPI, Basel, Switzerland. This article is an open access article distributed under the terms and conditions of the Creative Commons Attribution (CC BY) license (http:/ / creativecommons.org/licenses/by/4.0/). 